\title{
LETRAMENTO CRÍTICO E ENSINO INTERCULTURAL COMO PRÁTICAS RELEVANTES EM CONTEXTO DE INTERNACIONALIZAÇÃO: foco no planejamento de um curso de alemão como $L E$
}

\author{
Lívia dos Santos Marques ${ }^{1}$ \\ Cibele Cecilio de Faria Rozenfeld ${ }^{2}$
}

\begin{abstract}
Resumo
Diante de um cenário de internacionalização nas universidades, é importante que a comunidade acadêmica esteja preparada para o confronto com a diversidade cultural, e para tanto, defendemos que o letramento crítico e o ensino de línguas intercultural trazem uma nova perspectiva sobre a noção de língua, cultura e a educação. Essa nova visão pode transformar a maneira como o professor planeja aulas ou cursos de língua estrangeira (LE). Assim, este artigo tem como objetivo refletir teoricamente sobre o planejamento de cursos a partir das premissas do letramento crítico e ensino intercultural, e analisar o planejamento de curso de língua alemã realizado com base nessas teorias de ensino. Para tanto, apoiaremo-nos em autores que tratam sobre o planejamento de cursos de LE (DUBIN, OLSCHTAIN, 1986; ALMEIDA FILHO, 1997; RICHARDS, 2001; ALMEIDA FILHO, 2012), o letramento crítico (HAMMOND, MACKEN-HORARIK, 1999; SOUZA, 2011; JORDÃO, 2013; ROZENFELD, 2016) e o ensino de línguas intercultural (BYRAM, 1997; HOUSE, 2007; KRAMSCH, 2009; LIDDICOAT, 2011). A partir do estudo dos autores citados, realizamos uma pesquisa qualitativa e exploratória, com foco na análise do planejamento de um minicurso de seis horas, para alunos universitários de Letras, que consistiu na exibição e discussão da minissérie alemã Unsere Mütter Unsere Väter. Por meio da análise, foi possível notar que o planejamento seguiu os princípios do ensino intercultural estabelecidos no modelo de Byram (1997), e pretendeu alcançar os principais objetivos do letramento crítico, preparando o aluno, assim, para o contexto de internacionalização. Concluiu-se que, além de estar coerente com ambas as teorias, é necessário que o professor repense sua prática e execute projetos que estimulem o aluno a agir em favor da mudança social e cidadania.
\end{abstract}

Palavras-chave: Letramento crítico; Intercultural; Planejamento de cursos.

\section{CRITICAL LITERACY AND INTERCULTURAL EDUCATION AS RELEVANT PRACTICES IN THE INTERNATIONALIZATION CONTEXT: focus on a German as FL course planning}

\begin{abstract}
Faced with a scenario of internationalization in universities, it is important that the academic community is prepared to confront cultural diversity, and to that end, we argue that critical literacy and intercultural language teaching bring a new perspective on the notion of language, culture and education. This new vision might transform the way teachers plan foreign language (FL) classes or courses. Therefore, this article has as an objective to reflect on the theories about course planning from the premises of critical literacy and intercultural language teaching, as much as to analyze a German language course plan, which was based on such theories. Thus, we address to authors who approach FL course planning (DUBIN, OLSCHTAIN, 1986; ALMEIDA FILHO, 1997; RICHARDS, 2001; ALMEIDA FILHO, 2012), critical literacy (HAMMOND, MACKEN-HORARIK, 1999; SOUZA, 2011; JORDÃO, 2013; ROZENFELD, 2016) and intercultural language teaching (BYRAM, 1997; HOUSE, 2007; KRAMSCH, 2009; LIDDICOAT, 2011). From the study about the cited authors, we

\footnotetext{
${ }^{1}$ Universidade Estadual Paulista "Júlio de Mesquita Filho" (UNESP), Faculdade de Ciências e Letras, Araraquara - SP - Brasil. Mestranda no Programa de Linguística e Língua Portuguesa. ORCID $<$ https://orcid.org/0000-0003-3247-0018>. E-mail:

2 Universidade Estadual Paulista "Júlio de Mesquita Filho" (UNESP), Faculdade de Ciências e Letras, Araraquara - SP - Brasil. Docente. Programa de Pós-Graduação em Linguística e Língua Portuguesa (PPGLLP). ORCID < https://orcid.org/0000-0001-8915-9541>. E-mail: cibele.rozenfeld@unesp.br
} 
have executed a qualitative and exploratory research, having as focus the analysis of a 6 hours German minicourse to university students of Letras. The minicourse consists of the exhibition and discussion about the German miniseries Unsere Mütter Unsere Väter. Through analysis, it was possible to notice that the plan follows principles from the intercultural teaching model made by Byram (1997) and intends to reach critical literacy's main objectives, therefore preparing the student for the context of internationalization. Thereby, we conclude that, despite being in accordance with both theories, it is necessary that, through a plan review, the planner rethink the evaluation methods and, if possible, execute projects to stimulate the student to act in favor of social change and citizenship.

Keywords: Critical literacy; Intercultural; Course planning.

\title{
INSTRUCCIÓN CRÍTICA Y ENSEÑANZA INTERCULTURAL COMO PRÁCTICAS RELEVANTES EN CONTEXTO DE INTERNACIONALIZACIÓN: foco en la planificación de un curso de alemán como LE
}

\begin{abstract}
Resumen
Ante un escenario de internacionalización en las universidades, es importante que la comunidad académica esté preparada para la confrontación con la diversidad cultural, y para ello, defendemos que la literacidad crítica y la educación intercultural en la enseñanza de lenguas traen una nueva perspectiva sobre la noción de lengua, cultura y educación. Esta nueva visión puede transformar la forma en que el profesor planea clases o cursos de lengua extranjera (LE). Así, este artículo tiene como objetivo reflexionar teóricamente sobre la planificación de cursos a partir de las premisas de literacidad crítica y la educación intercultural, y analizar la planificación de curso de lengua alemana realizada con base en esas teorías de educación. Para ello, nos apoyamos en autores que tratan sobre la planificación de cursos de LE (DUBIN, OLSCHTAIN, 1986; ALMEIDA FILHO, 1997; RICHARDS, 2001; ALMEIDA FILHO, 2012), el letra crítico (HAMMOND, MACKEN-HORARIK, 1999 SOUZA, 2011; JORDÃO, 2013; ROZENFELD, 2016) e la educación intercultural (BYRAM, 1997; HOUSE, 2007; KRAMSCH, 2009; LIDDICOAT, 2011). A partir del estudio de los autores citados, realizamos una investigación cualitativa y exploratoria, con foco en el análisis del planeamiento de un minicurso de seis horas, para alumnos universitarios de Letras, que consistió en la exhibición y discusión de la miniserie alemana Unsere Mütter Unsere Väter. Por medio del análisis, fue posible notar que la planificación siguió los principios de la educación intercultural establecidos en el modelo de Byram (1997), y pretendió alcanzar los principales objetivos de literacidad crítica, preparando al alumno, así, para el contexto de internacionalización. Se concluyó que, además de estar coherente con ambas teorías, es necesario que el profesor repita su práctica y ejecute proyectos que estimulen al alumno a actuar en favor del cambio social y ciudadanía.
\end{abstract}

Palabras clave: literacidad crítica, Intercultural; Planificación de curso

\section{Introdução}

No contexto atual de intensas e rápidas trocas acadêmicas e interculturais, decorrentes de recursos tecnológicos cada vez mais sofisticados, bem como dos meios de transporte mais acessíveis, é de grande importância que a universidade prepare seus funcionários, docentes e discentes para o confronto com novas culturas. Esse fenômeno tem despertado a atenção de centros de pesquisa e agências de fomento, levando à identificação de um processo conhecido como "internacionalização acadêmica" das universidades. Finardi, Santos e Guimarães (2016) afirmam que 
(...) as universidades no mundo todo estão passando por um processo de reestruturação para se acomodarem a essa nova realidade imposta pela globalização/internacionalização, sendo que cada contexto e cada universidade experimenta um processo singular (...) (ibidem, 2016, p. 236)

De acordo com os autores, internacionalização pode ser definida como "o processo de integração de uma dimensão internacional, intercultural e global na missão ou função da educação superior" (KNIGHT, 2003 apud AMORIM; FINARDI, 2017). Finardi e Ortiz (2015) e Amorim e Finardi (2017) concordam, porém, que a barreira linguística, frequentemente, é um grande desafio a ser enfrentado em programas dessa natureza. Os autores elencam os aspectos micro, meso e macro da internacionalização, os quais concernem respectivamente três esferas concêntricas, a saber: a comunidade acadêmica, a instituição e o governo. Nesse viés, nosso interesse recairá, neste trabalho, sobre a esfera micro, ou seja, a comunidade acadêmica.

Marrara (2007), ao discorrer sobre a internacionalização, salienta que o termo, embora literalmente nos remeta ao simples fato de tornar-se internacional, deve ser compreendido a partir dos objetivos que subjazem a ele. De um lado, há um meramente institucional e mais mercadológico, ou seja, que busca aquisição de maior status e renome à instituição de ensino superior que se propõe a desenvolvê-lo. Por outro lado, as políticas de internacionalização podem ser vistas

(...) como ferramentas a serviço da formação de docentes, pesquisadores e discentes. Sob esse enfoque predominantemente acadêmico, ela permitiria a realização de experiências complementares ao processo educacional no âmbito da graduação e da pós-graduação. Esse processo de internacionalização para fins estritamente acadêmicos, pautar-se-ia, em última instância, pelo intuito de contribuir com o desenvolvimento da educação e da ciência, através da colaboração e da troca de experiências com agentes estrangeiros. (MARRARA, 2007, p.248. grifo nosso)

$\mathrm{O}$ autor pondera, no excerto, que o processo de internacionalização com enfoque acadêmico envolve grande complexidade, pois visa desenvolvimento da educação e formação docente e discente. Assim, no sentido micro, proposto por Amorim e Finardi (2017), acerca da internacionalização no nível da comunidade, entendemos que, quando esse fenômeno é compreendido por essa perspectiva, ele pressupõe formação discente e preparo da comunidade acadêmica para os contatos e a comunicação intercultural.

Considerando que aprender línguas não deve estar dissociado de compreender culturas, conforme já afirmado por diferentes autores (BYRAM, 1997; KRAMSCH, 2013; SALOMÃO, 2015), defendemos que o ensino de línguas pelo viés do Letramento Crítico e da Interculturalidade são caminhos importantes para o processo de internacionalização e para se 
preparar discentes para o cenário contemporâneo em que vivem as universidades. Dessa maneira, este artigo tem como objetivo realizar reflexões sobre o planejamento de cursos com base no Letramento Crítico e Ensino Intercultural, mais especificamente, analisar o planejamento de um minicurso, ministrado em contexto universitário, e voltado para o ensino de língua alemã pautado em tais premissas.

No tópico seguinte, faremos uma breve reflexão teórica sobre os conceitos Letramento Crítico e Ensino intercultural, seguida da discussão sobre o tema planejamento de cursos voltados para o trato da diversidade cultural. Na sequência, discorreremos, então, sobre os procedimentos metodológicos, a análise do planejamento e, por fim, apresentaremos as considerações finais.

\section{Reflexões Teóricas}

Conforme mencionamos, apresentaremos neste tópico os principais estudos referentes aos conceitos de Letramento Crítico e Ensino Intercultural. Em seguida, a fim de estabelecer as principais características de um planejamento que contemple ambos, articularemos os termos com estudos sobre o planejamento de cursos de língua estrangeira.

\section{Letramento Crítico e Ensino Intercultural}

Antes de apresentarmos o planejamento das atividades realizadas, é importante nos debruçarmos sobre os conceitos que as subjazem, a saber, a noção de letramento crítico (doravante LC) e de Ensino Intercultural (doravante EI).

Segundo Souza (2011), o LC é a "redefinição do processo de conscientização crítica" (idem, p. 293), que estimula uma visão que vai além do senso comum, levando o aluno a tornar-se crítico sobre sua própria perspectiva, fruto da cultura e da ideologia de sua comunidade. Reconhece-se, assim, que maneiras de pensar e viver no mundo são construídas socialmente e não verdades absolutas. Jordão (2007), por sua vez, define o LC como uma abordagem educacional pautada em "uma visão discursiva do mundo, que atribui um papel fundamental à língua no processo de entender ou interpretar nossas experiências.” (idem, p.91). Dessa maneira, a autora apresenta o importante papel da língua na reflexão e construção de novas interpretações. É necessário destacar, ainda, que a autora não considera o LC como uma abordagem do ensino de línguas, que pode dar origem a uma metodologia, mas como uma "perspectiva educacional" ou "filosofia da educação" (idem, 2013, p.71).

Portanto, concluímos que o LC é uma nova perspectiva para a Educação, na qual a linguagem é concebida como um meio de expressão e de construção de sentidos, os quais 
devem ser construídos pelos alunos por meio do uso da língua. O ensino de língua estrangeira (doravante LE) teria, portanto, um papel importante para o LC, uma vez que a LE é uma poderosa ferramenta para interpretação e expressão de significados.

Além disso, sendo construída em outro contexto sociocultural, a LE apresenta ao aluno uma nova perspectiva sobre o mundo. Por meio dela, ele pode ter acessso a sentidos diferentes daqueles transmitidos em sua própria sociedade, de forma que a visão do outro poderá lhe permitir construir uma nova perspectiva sobre a sua própria cultura. A compreensão sobre o outro, aliada à reflexão sobre si, leva ao desenvolvimento da competência intercultural (BYRAM,1997; HOUSE, 2007; LIDDICOAT, 2011). Tal competência é significativa no ensino intercultual, que orienta o professor a tratar língua e cultura de maneira integrada em sala de aula (LIDDICOAT, 2011).

Diferentemente do LC, o EI tem origem especificamente no campo do ensino de LE. Segundo Liddicoat (2011), há duas grandes orientações para o ensino de cultura nas aulas de língua: a cultural e a intercultural. Enquanto a primeira pretende que o aluno adquira conhecimentos sobre a cultura estrangeira, a segunda tem por objetivo que a aquisição desses conhecimentos transforme a identidade, valores e crenças do aluno sobre o mundo (LIDDICOAT, 2011). Assim, sendo que o EI parte desta última visão, entende-se que ele pode se tornar uma orientação para ensino de cultura em diversas abordagens ou perspectivas da educação de línguas, inclusive o LC.

O EI tem como objetivo central tornar o aluno de línguas um falante intercultual, ou seja, "uma pessoa que conseguiu se acomodar no Entre, que sabe e pode agir em sua cultura nativa e em outra adquirida em algum momento posterior" (HOUSE, 2007, p.19). Assim, esse falante é alguém que adquiriu uma maneira híbrida de negociar sentidos, transformando e enriquecendo sua visão do mundo por meio da visão do outro. Kramsch chama essa visão de "terceiro lugar", ao afirmar que

A pedagogia do aprendizado de línguas intercultural ajuda estudantes a contruir esse Terceiro Lugar fazendo conecções entre L1/C1 e a L2/C2; comunicando através de fronteiras linguisticas e culturais e identificando e explicando essas fronteiras; reagindo criticamente ao seus próprios comportamentos interculturais e sua própria identidade; e se responsabilizando por contribuir para comunicação através de línguas e culturas" (KRAMSCH, 2009, p.244) 
Embora tal noção já seja problematizada em outro texto da autora (KRAMSCH, 2011), ela surge também entre os estudos do LC, em referência às diferentes construções de sentidos a partir da linguagem (JORDÃO, 2013). A autora afirma que

O objetivo de se aprender uma LE pode ser caracterizado [na perspectiva do Letramento Crítico] como uma possibilidade imediata de se viver em um 'terceiro espaço', em uma situação de movimento constante entre procedimentos interpretativos e, portanto, também entre sentidos possíveis" (JORDÃO, 2013, p.77)

Assim, é possível compreender que, tanto conforme premissas do ensino intercultural quanto do Letramento Crítico, a linguagem e o conhecimento são tidos como constructos sociais, que podem ser alterados no encontro com o outro.

Embora os conceitos de LC e de EI não constituam abordagens de ensino de línguas (não resultando em métodos específicos), eles podem guiar as ações do professor em seu planejamento. Ambos podem fornecer subsídios importantes sobre o que é, como se aprende e como se usa a LE, assim como quais os principais resultados esperam-se de um aprendiz de línguas. Assim, uma vez que essas perspectivas prezam pelo ensino da linguagem como social e cultural, construtora de sentidos, ambas possuem como objetivo que o aluno encontre, por meio da LE, uma visão mais ampla e crítica de mundo, compreendendo diferenças linguísticas, culturais e ideológicas e aprendendo a lidar com elas.

Essa compreensão é necessária, segundo Myles e Cheng (2003), para melhor adaptabilidade ao contexto estrangeiro e ao atual cenário de internacionalização, pois poderá preparar o aluno para o contato com colegas e professores de universidades estrangeiras. Seguindo essa lógica, Stephen e Stephen (1992) afirmam que a ansiedade no contato com a cultura estrangeira pode ser reduzida se o professor de LE ajudar o aluno a lidar com diferenças culturais e reduzir visões etnocêntricas.

Tendo as reflexões apresentadas como norte, elaboramos, conforme mencionamos, um minicurso voltado para promover discussões sobre questões culturais entre alunos de alemão como língua estrangeira, visando desestabilizar verdades pré-concebidas, rever estereótipos, (re)pensar a própria cutura a partir do outro, desenvolver a criticidade etc. No item, a seguir, discutiremos o conceito de planejamento de cursos de línguas, antes de apresentar aquele relacionado ao programa em foco.

\section{Planejamento de cursos de línguas em perspectiva do letramento crítico e ensino intercultural}


Para se refletir sobre planejamento de um curso elaborado sobre os pilares do LC e EI, é pertinente fazer, inicialmente, algumas ponderações teóricas sobre o próprio processo de planejamento. Tal planejamento, sendo ele explicitado ou não por meio de um documento, parte primeiramente de uma abordagem do planejador. Segundo Dubin e Olshtain (1986), a visão do professor sobre a natureza da linguagem, do aprendizado de línguas e uma filosofia educacional-cultural são três dos fatores que afetam as decisões dos professores sobre os objetivos do currículo. Nesse sentido, o planejamento será diretamente influenciado pelo que o professor acredita ser o processo de ensino e de aprendizagem.

Richards (2001) também considera que determinadas crenças, valores e objetivos são a base para a fundamentação do curso. Para o autor, o planejamento deve incluir, também, informações sobre as noções do papel do professor e do aluno, além dos objetivos do curso e seus componentes de conteúdos. O autor defende, ainda, que o processo de planejamento parte de decisões sobre os níveis de conhecimento esperados por alunos antes e depois do curso. Em seguida, devem ser selecionados os conteúdos do curso, o escopo desses conteúdos (profundidade em que os temas serão abordados) e a sequenciação (ordem em que os conteúdos serão apresentados). Exemplos de sequenciação são: o planejamento "linear", no qual cada conteúdo é visto e finalizado em uma única unidade, e "circular", no qual tais conteúdos são retomados após algumas unidades (RICHARDS, 2011).

Para Almeida Filho (2012), por sua vez, no documento do planejamento devem estar presentes informações sobre o conteúdo e procedimentos que se apresentarão durante o curso, e que poderão evidenciar a abordagem do planejador. O planejamento inclui decisões sobre o conteúdo linguístico, procedimentos metodológicos e a reflexão sobre as experiências e resultados do curso. O processo de planejamento do curso, para o autor, parte primeiramente da definição do contexto em que o curso será aplicado (incluindo dados sobre os alunos, professores, escola e papel da língua-alvo na comunidade). Então, são definidos os objetivos do curso (não apenas linguísticos, como educacionais, psicológicos, culturais, entre outros). Por fim, são planejadas as unidades de maneira interligada e coesa, a partir de decisões sobre o tipo de planejamento, a sequenciação, materiais, métodos, avaliação, entre outros.

Para Dubin e Olshtain (1986), após os objetivos gerais, devem ser concebidos os objetivos específicos do curso, assim como o conteúdo linguístico, processos e ferramentas necessários e, também produtos ou resultados esperados ao final do programa.

Mediante os modelos dos autores citados, concluímos que o planejamento é uma ferramenta utilizada pelos professores de cursos de línguas, que parte de uma abordagem que o subjaz, e que possui uma estrutura específica, incluindo objetivos (gerais e específicos), 
procedimentos (sequenciamento, escopo, atividades, entre outros) e os materiais utilizados durante o processo de ensino e aprendizagem, além de avaliações necessárias para observar e refletir sobre os resultados obtidos.

\section{Letramento Crítico: conceito e planejamento de curso}

A fim de planejar um curso de língua e cultura estrangeira com base no LC deve-se, em primeiro lugar, ter estabelecidos determinados conceitos, como os de língua, ensino, aprendizagem, assim como do papel do aluno e professor. Veremos a seguir algumas reflexões sobre tais concepções pelo viés do LC.

Concepção de língua: conforme já foi mencionado, a língua não é tomada como objeto neutro, pois qualquer prática de uso da língua é, nessa perspectiva, ideológica, localizada em um contexto cultural e social. Assim, ela é vista não como um código, mas como um discurso (JORDÃO, 2013).

Concepções de ensino e aprendizagem e papel do professor e aluno: Street (2006) afirma que o modelo de ensino dos novos letramentos é um modelo ideológico, o qual considera o contexto social do aprendiz no processo de ensino. Nesse sentido, os papéis do professor e do aluno também se tornam diferentes, pois passa-se a considerar o contexto e os conhecimentos deste último, sendo necessário que ele, suas necessidades e interesses, tornem-se o centro do ensino. Assim, tanto professor como aluno têm o papel de construtores de sentidos por meio da língua, sendo importante que o professor não imponha suas ideias, mas valorize a diversidade de opiniões em sala de aula, preparando o aprendiz para a diferença e o conflito (SOUZA, 2011). É preciso escutar as opiniões do aluno também no processo de planejamento do curso. Dessa forma, o próprio aluno pode agir como planejador, tomando decisões sobre os conteúdos juntamente com o professor. Este é um guia nesse processo, provendo materiais e conhecimento linguístico necessários para o andamento do curso (FRYE,1999).

Objetivos: Tendo como base os conceitos e papéis expostos até então, podemos estabelecer também alguns dos principais objetivos de um planejamento de curso de línguas realizado com base no LC. Considerando o uso da LE, podemos dizer que um dos objetivos do LC é o aprendizado da língua para comunicação e reflexão. Segundo Jordão e Fogaça (2007) “é importante que os alunos possam usar a LE em contextos comunicativos, nos quais os significados e os procedimentos interpretativos utilizados para construí-los sejam enfatizados" (Ibidem, p.96). Portanto, o foco do ensino não está apenas em ajudar o aluno a comunicar-se em diferentes situações, mas em levá-lo a interpretar aquilo que está sendo dito e expressar suas opiniões e experiências de maneira articulada. 
Para que o aluno seja capaz de compreender e analisar discursos, assim como repondêlos, é necessário, porém, que ele esteja ciente da natureza cultural e ideológica da linguagem, sendo papel do professor elucidar tal natureza. Conforme Hammond e Macken-Horarick (1999) o papel do letramento crítico é "ajudar estudantes a desenvolver visões sobre as maneiras como essas relações ideologicas, identitárias e de poder funcionam na sociedade e as maneiras na qual a linguagem trabalha para reforçar e desafiar essas relações" (HAMMOND; MACKEN-HORARICK, 1999, p. 529, tradução nossa). Assim, o aluno deve compreender que a língua é utilizada como ferramenta para expressão de perspectivas culturais e ideologias, que diferem ou se assemelham às dele. Nesse contexto, a sala de aula torna-se um espaço de embates e de análise crítica sobre as ideias implícitas ou explícitas nos discursos próprios e do outro. É importante que o aluno compreenda que essas ideias não tem um valor intrínseco, mas atribuído, geralmente, de acordo com a posição social daqueles que o constroem.

Nesse sentido, chegamos a um terceiro objetivo do LC: gerar reflexão crítica, não apenas sobre os discursos do outro, como também sobre os próprios. Segundo Tagata (2007), "vemos, portanto, como o letramento crítico objetiva conscientizar o aluno sobre seu papel ativo na construção e reconstrução de sentidos, de modo que eles reflitam seus propósitos e perspectivas" (ibidem, p. 388). Assim, embora o aprendiz muitas vezes veja suas práticas, produtos e perspectivas culturais como naturais, ele deve ser capaz de refletir e relativizar aquilo que considera verdadeiro a partir da visão do outro.

Finalmente, tem-se, também, como objetivo do ensino de LE pela perspectiva do LC, capacitar o aluno para gerar mudança social. Conforme Jordão e Fogaça (2007),

O ensino/aprendizagem de línguas estrangeiras pode, assim, construir com
os alunos uma percepção de seu papel ativo na transformação da sociedade
[...] Ao questionar pressupostos e implicações de diferentes pontos de vista
na sociedade - e nos textos - e assim ampliar nossas perspectivas, é possível
que os alunos sejam capazes de também perceber-se enquanto sujeitos
críticos, capazes de agir sobre o mundo e seus sentidos. (ibidem, 2007, p.93)

A fim de atingir aos objetivos citados, algumas atividades já foram descritas por pesquisadores que trabalham com o LC, como o compartilhamento de experiências (FRYE, 1999; ROZENFELD, 2016), a produção de textos escritos (HAMMOND, MACKENHORARIK, 1999; ROZENFELD, 2016), diálogos, discussões e debates (DUBOC, FERRAZ, 2011; JORDÃO, FOGAÇA, 2007), Role-play (FRYE, 1999) e atividades de interpretação multimodal (DUBOC, FERRAZ, 2011; JORDÃO, FOGAÇA, 2007). Já em relação aos 
materiais, destacamos o uso de filmes e vídeos (JORDÃO, FOGAÇA, 2007; ROZENFELD, 2016), textos na língua-materna (DUBOC, FERRAZ, 2011), textos autênticos e pedagógicos da língua alvo (HAMMOND, MACKEN-HORARIK, 1999; ROZENFELD, 2016; MARQUES e ROZENFELD, 2018), assim como fotos, gráficos e outras imagens (DUBOC, FERRAZ, 2011; FRYE, 1999)

Em decorrência da ausência de uma metodologia para o trabalho com o LC em aulas de LE, surge a questão acerca da forma de se abordar a gramática em sala de aula. Sobre isso, Jordão e Fogaça (2007) sugerem que ela deve ser ensinada conforme as necessidades e dúvidas dos alunos, as quais surgem naturalmente quando eles tentam construir novos sentidos. No entanto, entendemos que tal procedimento não seja sempre possível, tendo em vista exigências institucionais que comumente são colocadas ao professor, como o cumprimento de determinado número de lições ou o trato de estruturas linguísticas específicas. Assim, defendemos uma forma híbrida, que não se abstenha de abordar o conteúdo exigido, mas que encontre espaço para a reflexão e participação do aluno em seu processo de aprendizagem.

\section{Ensino intercultural: conceito e planejamento de curso}

De maneira semelhante ao tópico anterior, estabeleceremos, a seguir, alguns dos principais conceitos e objetivos do ensino intercultural.

Concepção de língua: Conforme mencionado anteriormente, o ensino de línguas intercultural pretende que o aluno se torne um falante intercultural, tornando-se um mediador entre língua e culturas maternas e estrangeiras. Ela não é apenas, portanto, uma forma de comunicação, mas um dos principais meios pelo qual a cultura se expressa (TAVARES, 2006), contendo sentidos próprios, a depender do contexto histórico, social e ideológico em que é utilizada, os quais o aluno deve saber notar, analisar e respeitar.

Concepções de ensino e aprendizagem e papéis do aluno e professor: Para que o falante torne-se intercultural, é necessário que o aluno tenha autonomia para realizar suas próprias reflexões sobre a sua própria cultura e a do outro (CROZET, LIDDICOAT, 1999), de forma que o professor não seja o único a expressar suas próprias interpretações sobre as práticas e produtos culturais. Dessa maneira, Crozet e Liddicoat (1999, p.122) afirmam que "como o EI também envolve autoreflexão [...] o melhor ambiente de sala é aquele que favorece uma abordagem centrada no aluno, a qual, contudo, não diminui a necessidade do aluno em ser ensinado sobre a cultura no uso linguístico". Assim, o ensino intercultural vê o papel do aprendiz como central na aprendizagem. Ele torna-se reflexivo, se engaja em seu aprendizado 
e construção de conhecimento (LIDDICOAT, 2011). Por outro lado, o professor bem informado, tem o papel de apresentar conteúdos sobre os produtos, práticas e perspectivas culturais ao aluno e orientá-lo no processo de reflexão sobre a cultura-alvo e a própria. (CROZET, LIDDICOAT, 1999)

Objetivo: Para que o aprendiz de línguas se torne um falante intercultural, segundo Byram (1997), ele deve adquirir a competência comunicativa intercultural (Intercultural Comunicative Competence, doravante ICC). O autor sugere, então, um modelo de ICC, no qual a competência é adquirida a partir do desenvolvimento de atitudes, conhecimentos, habilidades e uma consciência crítica cultural. Segundo Byram (1997), as atitudes são relativas à curiosidade do aluno sobre a língua e cultura estrangeiras, abertura às perspectivas, produtos e práticas do outro e disposição para relativizar "verdades" de sua própria cultura. Os conhecimentos são relativos aos produtos e práticas culturais, grupos sociais, história, geografia e instituições de importância, tanto da cultura estrangeira como da própria. As habilidades podem ser divididas em habilidades de interpretar e relacionar, assim como habilidades de descobrir e interagir. As primeiras são aquelas de interpretar um documento ou evento da cultura estrangeira e relacioná-lo com a própria. As segundas, por outro lado, são a capacidade de descobrir novas informações, práticas e perspectivas, muitas vezes implicitas no discurso, e usá-las na interação com o outro. Por fim, a consciência crítica cultural ou educação política, é a análise crítica em relação a perspectivas e práticas presentes em documentos ou eventos da cultura própria e estrangeira, tendo como base os direitos humanos. (BYRAM, 1997).

A fim de desenvolver a ICC em cursos de LE, o autor sugere que o planejamento destes siga os seguintes estágios: primeiramente, faz-se uma análise das necessidades dos alunos, do local em que se dará o aprendizado, assim como do interesse e disposição dos aprendizes para aquisição da ICC. Em seguida, deve-se selecionar os objetivos do currículo, escolhendo quais competências linguísticas, habilidades, atitudes e conhecimentos serão priorizados, relacionando esses objetivos às primeiras análises citadas. Por fim, deve-se sequenciar o conteúdo a partir dos objetivos que devem ser priorizados, ainda que não de maneira linear e cumulativa.

Embora o autor não destaque atividades e materiais específicos a serem utilizados no planejamento proposto, podemos citar algumas das experiências de professores e estudiosos do ensino intercultural. Entre as principais atividades utilizadas para desenvolvimento da ICC, podemos destacar discussões e diálogos em sala de aula (GALANTE, 2015; KRAMSCH, 2003), produção escrita (GALANTE, 2015; KRAMSCH, 2003), comunicação com 
estrangeiros por meio, por exemplo, da realização de tandem ${ }^{3}$ (KRAMSCH, 2013, O’DOWD, 2011), além de atividades que levem a reflexões e comparações entre semelhanças e diferenças culturais (CROZET, LIDDICOAT, 1999; OLIVEIRA, 2012).

Por fim, para a avaliação do aluno, Liddcoat (2011) afirma que, entre as formas mais comuns, estão o role-playing, as simulações e outras atividades que busquem explicitar a habilidade do aluno em mediar entre duas línguas. Porém, segundo o autor, esse tipo de tarefa, embora avalie o desempenho do aluno, não deixa claro que o aluno é capaz de refletir sobre as relações entre a cultura própria e do outro. Ele sugere, então, que a avaliação seja realizada de maneira contínua, não apenas por meio de uma tarefa comunicativa, mas de diversas formas ao longo do curso e reunidas em um portifolio. O autor também destaca a importância da autoavaliação neste contexto.

A partir das teorias expostas até esse ponto, realizamos a análise de dados conforme os procedimentos metodológicos apresentados no tópico seguinte.

\section{Procedimentos Metodológicos}

Este trabalho se origina de uma pesquisa de caráter qualitativo e exploratório. A pesquisa qualitativa é aquela cujos resultados são obtidos de maneira indutiva, partindo de uma análise subjetiva do pesquisador, e não do uso de números (DAFOLVO, LANA, SILVEIRA, 2009). Já a exploratória caracteriza-se por investigar um tema sobre o qual ainda não se tem muitas informações e que, portanto, necessita de uma análise mais aprofundada. (idem)

A pesquisa se desenvolveu a partir das seguintes etapas: primeiramente, realizou-se uma revisão bibliográfica sobre teorias sobre o planejamento de cursos de LE (DUBIN, OLSCHTAIN, 1986; ALMEIDA FILHO, 1997; RICHARDS, 2001; ALMEIDA FILHO, 2012), o letramento crítico (HAMMOND, MACKEN-HORARIK, 1999; SOUZA, 2011; JORDÃO, FOGAÇA, 2007; JORDÃO, 2013; ROZENFELD, 2016) e o ensino intercultural (BYRAM, 1997; HOUSE, 2007; KRAMSCH, 2009; LIDDICOAT, 2011). Em seguida, fez-se a análise do planejamento de um minicurso de língua alemã (Apêndice 1), a fím de compreender de que maneira ele atende aos critérios de um planejamento alinhado às teorias do Letramento crítico e do Ensino Intercultural. Por fim, na terceira parte, verificamos em que

\footnotetext{
${ }^{3}$ Aprendizado Tandem é essencialmente uma atividade de aprendizado de línguas que envolve troca linguística e colaboração entre dois parceiros que são falantes nativos da língua-alvo de seus parceiros." (O’DOWD, 2011, p. 341, tradução nossa)
} 
medida o curso desenvolvido está de acordo com premissas do LC, do EI e da internacionalização nas universidades e como essa proposta poderia beneficiar tal processo.

Destaca-se que o planejamento escolhido para análise se refere a um minicurso, que foi realizado como etapa piloto de uma pesquisa de mestrado, que tem como foco o desenvolvimento da competência comunicativa intercultural por meio da minissérie televisiva alemã Unsere Mütter Unsere Väter ${ }^{4}$ em aulas de língua alemã. As atividades foram selecionadas a partir do visionamento da minissérie como um todo e, depois, foram selecionadas algumas cenas e definidas as atividades anteriores, simultâneas e posteriores à sua exibição. O planejamento foi elaborado pela pesquisadora/planejadora para aplicação das aulas piloto da coleta de dados de sua pesquisa.

O minicurso teve duração de 6 horas e foi ministrado na Universidade Estadual Paulista Júlio de Mesquita Filho (UNESP), para alunos do nível A1 de alemão no curso de Letras-alemão. O planejamento desenvolveu-se a partir da proposta de exibir e discutir o primeiro episódio da minissérie Unsere Mütter Unsere Väter e despertar a reflexão crítica do aluno sobre eventos e documentos sobre a cultura estrangeira e a própria.

Sobre a minisséire Unsere Mütter Unsere Väter, é importante salientar que se trata de um programa televisivo alemão, exibido pela primeira vez no ano de 2013, na Alemanha, e que apresenta a história de cinco amigos durante a Segunda Guerra Mundial, a partir da perspectiva desses alemães. No tópico seguinte, trataremos, então, da análise do planejamento selecionado.

\section{Análise do Planejamento do minicurso}

O planejamento do minicurso passou, primeiramente, pela apreciação da professora responsável pela sala, e encontra-se em anexo no Apêndice 1 deste trabalho. Nele foram incluídos os seguintes itens descritores: 1) Descrição geral do curso; 2) Público-alvo; 3) Material a ser utilizado; 4) Duração do curso 5) Objetivo geral; 6) Objetivos específicos;; 7) Descrição das atividades por aula, incluindo a exibição de uma cena do episódio (e as atividades pré, durante e pós exibição). $\mathrm{Na}$ descrição geral do planejamento a professora/pesquisadora deixou explícitas suas concepções de língua e cultura, além de apresentar o contexto do curso (público-alvo) e, materiais necessários em um planejamento

\footnotetext{
4 Em português "Filhos da Guerra" ou "Generation War", em inglês. Mais sobre a série, por exemplo em https://pt.wikipedia.org/wiki/Generation War ou em https://www.imdb.com/title/tt1883092/
} 
(ALMEIDA FILHO, 2011), bem como conteúdos e sequenciação (RICHARDS, 2001), pensados com o intuito de atingir a objetivos gerais e específicos descritos no documento (DUBIN, OLSHTAIN, 1986), por meio de procedimentos específicos (atividades descritas). A partir de então, analisaremos se tais aspectos essenciais no planejamento se dão de acordo com os princípios da LC e EI.

A descrição geral é elaborada da seguinte maneira pela Professora/pesquisadora:

\begin{abstract}
O minicurso tem como foco o ensino e reflexão sobre as culturas alemãs e brasileiras para alunos iniciantes de língua alemã. Nesse contexto, a cultura estrangeira é ensinada não apenas com o objetivo de evitar-se um mal-entendido na comunicação, mas também para levar o aluno a criação de uma nova perspectiva sobre si e o outro, desafiando conhecimentos e concepções prévias.
\end{abstract}

Avaliando a proposta, com os objetivos e atividades, foi possível notar que a professora/pesquisadora teve como pilares principais a noção de língua como meio de comunicação e ferramenta para interpretação de sentidos e reflexão, bem como que partiu da premissa de que cultura é um conceito importante em sala de aula, uma vez que um dos objetivos é o desenvolvimento da competência intercultural. A cultura foi tida como plural e heterogênea (SALOMÃO, 2015) e o ensino de cultura estrangeira é visto como uma ferramenta para interpretação, reflexão e para ampliação dos conhecimentos do próprio aluno sobre si e o outro, conforme premissas de Kramsch (2009), Byram (1997) e Liddicoat (2011).

Nota-se, na descrição das atividades, que a professora/pesquisadora pressupõe o aluno como agente em sala de aula, que deve expressar suas opiniões e participar das atividades preparadas pelo professor, assim como propor novos temas e atividades. A partir dos procedimentos de aula delineados, fica claro que o professor não é considerado o centro da aprendizagem, uma vez que tal papel é assumido frequentemente pelo aluno, agente ativo em seu próprio aprendizado, conforme exemplos em excertos a seguir:

\footnotetext{
*(...) Colocar o título "Unsere Mütter Unsere Väter" na lousa e pedir que os alunos opinem sobre o que se trata a série.

*(...) perguntar quais das suas impressões sobre os personagens mudaram e quais se mantiveram.

*Dividir os alunos em 5 grupos para elaborar uma "Rad der Identität" (Roda da identidade) dos protagonistas da minissérie. A partir das rodas elaboradas na lousa, fazer perguntas que levem os alunos a discutir como se deu a perda ou não de determinados aspectos da identidade dos personagens durante os acontecimentos da minissérie, em especial após as repressões do regime nazista e os eventos nos frontes de guerra.
} 
A partir da análise dos pressupostos descritos até esse ponto, podemos concluir que os conceitos de língua, cultura, a concepção de ensino e de aprendizagem estão em concordância com as premissas do LC e o EI. O conceito de língua parte de uma perspectiva discursiva, pois, conforme a descrição geral, seu uso permite não apenas a comunicação, mas a expressão de diferentes ideias, valores e intepretações. O conceito de cultura é visto como uma construção social que deve ser, por vezes, ser questionada a partir da visão do outro (LIDDICOAT, 2011). Foi contemplado também o papel do aluno como construtor de sentidos e planejador (FRYE, 1999). O primeiro pôde ser observado devido ao foco do planejamento na interpretação e reflexão dos alunos sobre a minissérie, e o segundo, no fato de que os alunos deveriam guiar as discussões em sala de aula.

Destaca-se que, em se tratando do público-alvo descrito, este é composto por alunos universitários de Letras, cursando a língua alemã no nível A1. Esses alunos são, portanto, não apenas aprendizes da LE, mas professores de línguas estrangeiras (alemão) em formação. Tanto o EI (BYRAM, 1997) quanto o LC (FRYE, 1999) defendem o importante papel da análise das necessidades do público-alvo e do local de aprendizado. Nesse sentido, vale reiterar o momento de internacionalização que vive a universidade e, também que é notável no mundo. Torna-se cada vez mais necessário, assim, a formação inicial de discentes (e em formação continuada) para a compreensão da diversidade e para a tolerância. Porém, notamos que, embora o público proposto para o planejamento fosse de professores de alemão em formação inicial, não encontramos nenhuma atividade que visasse incitar os alunos a uma reflexão sobre a prática docente, como por exemplo, sobre formas de abordar a temática do holocausto, da ditadura, ou do período hitleriano, em sala de aula de alemão como LE.

Quanto aos materiais, citados no item 3 do planejamento, por sua vez, estes incluem, além da minissérie em foco, lousa, materiais fotocopiados, aparelhos celulares, computador e data-show. A diversidade de materiais permite que o aluno tenha acesso a diversas modalidades de texto (como áudios, vídeos, imagens ou textos escritos), os quais, por sua vez, expressam sentidos por meio de linguagens multimodais. O contato e a interpretação do aluno sobre tais materias, portanto, pode ajudá-lo a refletir sobre a maneira como sociedades e culturas diferentes constroem seus discursos, sendo tais reflexões benéficas nas perspectivas do LC (JORDÃO, 2013) e EI (TAVARES, 2006).

Em relação aos objetivos gerais e específicos, notamos que neles são claramente definidas as atitudes, habilidades e conhecimentos que se pretendeu alcançar ao longo do curso, conforme necessário no planejamento em um currículo do EI (Byram, 1997), e os quais estão alinhados também com premissas do LC. O Obetivo Geral do planejamento contempla o 
desenvolvimento da reflexão crítica por meio da discussão em sala de aula, capacitando o aluno para uso da língua como ferramenta de comunicação e expressão, conforme um dos objetivos do LC. Tais fatos podem ser verificados na descrição dos objetivos apresentados a seguir (grifos nossos).

Objetivo geral: desenvolvimento da reflexão crítica e competência intercultural no aluno de alemão a partir do visionamento e discussão da minissérie Unsere Mütter Unsere Väter.

Objetivos específicos: Possibilitar o desenvolvimento das seguintes atitudes, conhecimentos e habilidades dos alunos: 1. Abrir-se para novas perpectivas sobre a cultura e história alemã; 2. Adquirir conhecimentos sobre a memória nacional da Alemanha; 3. Expressar interpretações sobre o desenvolvimento da narrativa e dos personagens da minissérie; 4. Relacionar acontecimentos representados na minissérie com a realidade presente do aluno; 5 . Revisar preconceitos e estereótipos sobre a culturaalvo.

Nota-se, a partir de nossos grifos nos excertos, que a proposta teve como propósito auxiliar o desenvolvimento da consciência crítica cultural do aluno, pois visava que o aprendiz refletisse sobre e avaliasse criticamente ações e ideologias próprias e dos personagens em cena.

Entre as atividades propostas para alcançar o objetivo geral, podemos destacar a construção da roda da identidade, na qual os aprendizes puderam expor e debater suas percepções acerca dos personagens, bem como refletir sobre o que consideravam parte da identidade de um indivíduo (nacionalidade? religião? gostos? características pessoais? relacionamentos? papéis familiares?) e sobre a forma como esses fatores influenciam as práticas dos personagens e as próprias.

Assim, seguimos para a análise dos cinco objetivos específicos (doravante OE) destacados no planejamento: o OE 1 foi elaborado a fim de estimular o aluno a uma abertura à cultura estrangeira. Notamos que tal objetivo está ligado às atitudes de abertura e curiosidade necessárias para o desenvolvimento da ICC do modelo de Byram (1997). Também está relacionado ao objetivo de desenvolvimento do Letramento Crítico, no que tange à elucidação da linguagem como discurso de caráter cultural e ideológico, na medida em que o referido $\mathrm{OE}$ parte do pressuposto de que a cultura estrangeira constrói sentidos de maneira diferente da cultura materna. Tais sentidos, contudo, não devem ser considerados falsos ou incorretos, pelo contrário, o aluno deve abrir-se a eles. As atividades propostas a fim de se alcançar o OE 1 incluíram a discussão sobre a escolha do nome da minissérie "Unsere Mütter Unsere Väter", pois estimula o aluno a refletir sobre o significado da Segunda Guerra Mundial para os 
alemães, evento que está relacionado ao seu passado, sua memória, sua descendência (que, possivelmente, se difere do sentido de um brasileiro, por exemplo, sobre o mesmo evento).

Já o OE 2 trata da construção de conhecimentos sobre a cultura alemã. Ele se relaciona, portanto, aos conhecimentos necessários para desenvolvimento da ICC, como aqueles sobre a memória nacional dos países falantes da língua-alvo. No sentido de adquirir tais conhecimentos, foram propostas atividades de pesquisa online, por exemplo, sobre os grupos Partisans ${ }^{5}$ e o movimento Rosa Branca $^{6}$ (Weiße Rose). Para tal pesquisa os alunos tiveram que utilizar seus próprios aparelhos celulares ou tablets, a fim de obterem informações. Tal atividade pôde ser realizada em grupo, uma vez que buscou-se promover a interação e também se considerou a possibilidade de que alguns alunos não tivessem celulares no momento da atividade, e nesse caso, poderiam, ainda assim, participar da atividade, com ajuda dos aparelhos dos colegas.

É importante destacar, ainda, que o uso da internet, celulares e outros aparelhos eletrônicos em sala de aula caracteríza-se por aprendizagem móvel ${ }^{7}$. Nesse contexto, a aprendizagem móvel é planejada com antedência e guiada pelo professor. Segundo Leffa e Iralla (2014), para que sejam obtidos bons resultados na prendizagem mediada por celulares,

(...) não basta dar o celular ao aluno; é também necessário que haja planejamento. [...] Não basta a presença dos recursos; é necessário que haja também uma ação intencional que inicialize o processo de aprendizagem, deixando claro aonde se quer chegar. (Ibidem, p. 37)

Assim, a aprendizagem móvel é utilizada aqui com o objetivo claro de levar o aluno a tornar-se agente em seu próprio aprendizado sobre conhecimentos da cultura alemã, mais especificamente, da história desse país.

\footnotetext{
${ }^{5} \mathrm{Na}$ política, o termo partisan significa, literalmente, grupo organizado em um partido político. Durante a Segunda Guerra Mundial, porém, recebia o nome de partisan (plural partisans) todo o grupo paramilitar, geralmente sem qualquer treinamento regular, formado com o intuito de resistir à intensa ocupação das forças alemãs durante o conflito. Estes grupos eram geralmente constituídos por trabalhadores, gente comum que se reunia a algum grupo um pouco maior com outros trabalhadores e seguiam tentando dar alguma forma de apoio às forças regulares envolvidas na guerra. In: Infoescola. Disponível em: https://www.infoescola.com/politica/partisans/ Acesso em 26 out. 2018.

${ }^{6}$ Rosa Branca (em alemão: Weiße Rose) foi um movimento antinazista da resistência alemã, não-violento, de inspiração católica surgido na Alemanha durante a Segunda Guerra Mundial. Os seus membros mais notórios foram Sophie Scholl, Hans Scholl, Alexander Schmorell, Willi Graf, Christoph Probst e o Prof. Kurt Huber. Todos eles foram guilhotinados pela Gestapo em 1943 depois de Sophie ser presa com panfletos antinazistas. Seus panfletos tinham trechos do apocalipse e frases antinazistas e eram deixados nas caixas de correio. In: Wikipedia. Disponível em: https://pt.wikipedia.org/wiki/Rosa_Branca . Acesso em 26 out. 2018.

7 De acordo com Marques-Schäfer e Rozenfeld (2018), a Unesco (2014) definiu a aprendizagem móvel como aquela que "envolve o uso de tecnologias móveis, isoladamente ou em combinação com outras tecnologias de informação e comunicação (TIC), a fim de permitir a aprendizagem em qualquer hora e em qualquer lugar" (MARQUES-SCHÄFER; ROZENFELD, 2018, p.63)
} 
Em relação ao $\mathrm{OE} \mathrm{3,} \mathrm{o} \mathrm{minicurso} \mathrm{pretendeu} \mathrm{que} \mathrm{os} \mathrm{alunos} \mathrm{expressassem} \mathrm{suas}$ interpretações acerca dos acontecimentos da minissérie. Tal OE atende, portanto, a uma das propostas do letramento crítico, que trata do uso da língua para expressão, uma vez que o aluno deve compreender a linguagem utilizada na minissérie e ainda utilizar seus conhecimentos linguísticos em alemão para expor sua interpretação do material ${ }^{8}$. Destaca-se, ainda, que o OE 3 pode auxiliar na promoção da interação e da descoberta de perspectivas e práticas explícitas ou implícitas presentes na cultura alemã, elementos necessários para o desenvolvimento da ICC.

Atividades como a organização de cenas do episódio em "Expectativas" dos alemães sobre a guerra ou sobre o regime nazista e as "Realidades" com a qual se depararam no desenvolvimento da série, podem ajudar o aluno a refletir e discutir em grupos os acontecimentos da minissérie, assim como relacionar esses momentos entre si, para que compreendam de que maneira a narrativa e os personagens se desenvolveram. Uma vez que não há, necessariamente, uma resposta certa ou interpretação única durante a atividade, os alunos podem sentir-se livres para exercer seus papéis de construtores de sentidos.

O OE 4 trata do desenvolvimento da habilidade de relacionar os acontecimentos da minissérie com aqueles da realidade do próprio aluno. Assim, o OE proposto era levar o aluno a avaliar as semelhanças e diferenças sociais e culturais entre as culturas alemãs e brasileiras, assim como o proposto pela habilidade de interpretar e relacionar exigida na aquisição da ICC (BYRAM, 1997). Também é possível associar tal OE com o objetivo de reflexão sobre si o outro necessário no LC (TAGATA, 2007). Nesse sentido, o planejamento sugere que, ao final das discussões sobre cada tema, o aluno reflita sobre os problemas enfrentados por si ou pela sociedade brasileira em geral, a partir das situações em que se encontram os personagens. Tais discussões podem auxiliar o aprendiz a compreender que, mesmo em meio a diferenças culturais, os falantes da língua estrangeira têm sentimentos, ideais, ou enfrentam problemas semelhantes aos seus (muitas vezes relacionados a própria condição humana), sendo necessário, portanto, tratá-los, não como estranhos, mas como iguais.

O OE 5, por fim, relacionado à revisão de preconceitos e estereótipos, foi elaborado com o intuito de auxiliar o professor a elucidar a natureza ideológica e cultural da linguagem, mostrando ao aprendiz, que suas imagens sobre o outro são constuídas socialmente e necessitam, muitas vezes, ser revisadas mediante o contato. Esse processo de revisão, segundo

\footnotetext{
${ }^{8}$ Ainda que as discussões mais complexas tivessem sido realizadas em português, os alunos usaram estruturas básicas do alemão, conforme planejamento em anexo, como "denn", "es geht um", "sie/er ist +adjetivo" e outras.
} 
Byram (1997), pode gerar atitudes de abertura e curiosidade sobre a cultura estrangeira, pois passa-se a enxergar o outro como um indivíduo complexo dentro de uma cultura abrangente e não apenas como uma imagem estável e superficial. A atividade sugerida de comparação entre as primeiras impressões (nas quais estereótipos podem emergir na fala dos alunos) e as impressões finais dos personagens, podem ajudá-los a compreender que os indivíduos representados na minissérie vão além de suas visões prévias.

Sobre o OG e os OEs destacados, é preciso salientar, ainda, a ausência, no planejamento do curso, de um projeto que estimule diretamente a ação social. Apesar disso, o desenvolvimento da consciência crítica cultural (presente no OG e estimulado por meio da reflexão sobre si e o outro) pode favorecer a conscientização do aluno sobre os problemas enfrentados na sua e/ou em outras sociedades, podendo, assim, gerar mudança social, conforme o último objetivo do letramento crítico (JORDÃO; FOGAÇA, 2007).

Tendo esclarecido como os objetivos podem ser alcançados por meio das atividades descritas no planejamento, resta ainda ressaltar que a organização e sequenciamento de tais atividades pode ser considerada circular (RICHARDS, 2001), uma vez que houve a possibilidade de ensino e revisão de determinadas estruturas durante o minicurso, por exemplo, nas expressões "ich denke/glaube", em português, "eu acho/eu penso", ou "es geht um/ es ist über", em português, "trata-se de". Notou-se também que determinado vocabulário pôde ser retomado, principalmente em momentos destinados ao esclarecimento de dúvidas sobre palavras presentes na minissérie. Nessas partes do curso, termos referentes ao tema da Segunda Guerra Mundial emergiram mais de uma vez, por exemplo, Krieg (Guerra), schießen (atirar), Panzer (tanque), Soldat (Sodado) Krankenschwester (Enfermeira), entre outros.

Quanto à avaliação sugerida no planejamento, enfatiza-se, primeiramente, que o minicurso não tem caráter avaliativo ou reprobatório, sendo a avaliação, neste caso, uma forma dos alunos compreenderem e refletirem sobre seu próprio desenvolvimento. Também auxiliará o professor a analisar as atividades realizadas durante o curso e, se necessário, reelaborá-las, para que atinjam os objetivos de maneira satisfatória. Dessa forma, a professora/pesquisadora, sugeriu a escrita de um texto em língua materna ou uma autoavaliação em língua alemã. Essa última, porém, poderia não estar adequada ao nível de conhecimento linguístico A1 dos alunos, uma vez que, nesse nível, não se espera que o aluno seja capaz de escrever sentenças longas em língua alemã. É necessário destacar, que ambas as avaliações pareceram ter como objetivo avaliar o desenvolvimento da criticidade e competência intercultural. Assim, para avaliar a competência linguística do aluno, seria mais adequada uma avaliação separada, que testasse a compreensão de estrutura e vocabulário 
apresentados durante o minicurso. Também poderia ser viável realizar uma série de pequenas atividades, tornando a avaliação menos pontual e mais procedural, conforme sugerido por Liddicoat (2011).

Tratando-se, enfim, da relevância do planejamento no contexto da internacionalização, percebemos que os objetivos gerais e específicos têm como foco preparar o aluno para o encontro com o estrangeiro, de maneira a estimular a reflexão e a tolerância. Embora conflitos de valores, ideias e práticas sejam comuns no contato direto com o outro, como ocorre na internacionalização, por meio do ensino intercultural e do letramento crítico pretende-se que os alunos aprendam a lidar com essas situações de conflito, tornando-se mediadores entre a sua e a outra cultura (BYRAM, 2011). Além disso, a revisão de estereótipos pretendida por algumas das atividades apresentadas pode ajudar o aluno a tornar-se mais aberto à cultura estrangeira e, portanto, adaptar-se melhor no contexto de um novo país (STEPHEN, STEPHEN, 1992). Nesse sentido, o planejamento realizado torna-se adequado para o público universitário que pretende buscar um intercâmbio ou que se deparará com estrangeiros da comunidade acadêmica.Ainda é importante destacar, que o processo de internacionalização é uma via de mão dupla, ou seja, ao mesmo tempo em que preparamos os alunos para a especialização em universidades estrangeiras, devemos também prepará-los para receber os alunos estrangeiros que chegam às universidades brasileiras. Nesse sentido, o minicurso planejado também nos parecei de valia, uma vez que, em consonância com Myles e Cheng (2003), é necessário que os alunos e professores da universidade tenham uma visão mais ampla da diversidade cultural e, por meio de um ensino intercultural, aprendam a lidar com tais diferenças para promover a inclusão dentro da universidade.

\section{Considerações Finais}

Este trabalho teve como objetivo apresentar e analisar o planejamento de um curso de alemão voltado para o desenvolvimento do Letramento Crítico e da Competência Comunicativa Intercultural (BYRAM, 1997), por meio do trabalho com a minissérie alemã "Unsere Väter, unsere Mütter" (Filhos da Guerra, em português), em um contexto de internacionalização de uma universidade pública. A partir das reflexões teóricas e análises realizadas, pudemos concluir que o minicurso está coerente com as premissas de tais conceitos, tendo em vista que fomentaram a reflexão crítica sobre a cultura estrangeira e sobre a própria, bem como sobre temas como identidade, estereótipos, entre outros. Nesse sentido, as reflexões críticas realizadas sobre as culturas alemãs e brasileiras podem colaborar para que o aluno adquira a competência comunicativa intercultural e relativize aquilo que considera 
verdade sobre si e o outro, revisando possíveis estereótipos e obtendo uma visão menos etnocêntrica do mundo. Essa visão poderá auxiliar o aluno em meio a encontros interculturais decorrentes da internacionalização das universidades, que inclui experiências de intercâmbio, assim como a inclusão de intercambistas nas universidades brasileiras.

Em relação ao andamento da pesquisa, na qual o planejamento se insere, considerando que este foi realizado da fase piloto, a análise realizada poderá contribuir no desenvolvimento do planejamento para a coleta de dados. Nesse sentido, será necessário que, antes da aplicação desta, o planejador dê especial atenção a reelaboração do método de avaliação, para que esta avalie tanto a criticidade e ICC do aluno, quanto seu desenvolvimento linguístico. Também sugere-se que a professora/pesquisadora reflita sobre a possibilidade de um projeto prático (por exemplo, uma exposição de cartazes, vídeos, ou outras produções próprias do aluno), no qual os aprendizes possam, além de desenvolver a habilidade crítica e competência intercultural, realizar ações que possibilitem mudança social. Uma ação em parceria com outras disciplinas ou turmas poderia, por exemplo, permitir que as reflexões realizadas em sala de aula não permaneçam apenas entre os alunos, mas possam ter impacto no ambiente escolar ou universitário como um todo.

Esperamos, assim, com este trabalho, ser possível contribuir para estudos acerca do processo de internacionalização nas universidades, sobre o Letramento Crítico em sala de aula de língua estrangeira e sobre o desenvolvimento da competência comunicativa intercultural.

\section{Referências}

ALDA, L. S. LEFFA, V. J. Entre a carência e a profusão: aprendizagem de línguas mediada por telefone celular. Conexão - Comunicação e Cultura, v.13, n. 26, p.75-97, 2014.

ALMEIDA FILHO, J. C. P. A abordagem orientadora da ação do professor. In: ALMEIDA FILHO, J. C. P. (org) Parâmetros Atuais Para o Ensino de Português Língua Estrangeira. Pontes. Campinas, 1997, p.13-28.

ALMEIDA FILHO, J. C. P. Planejamento de cursos de línguas(s): prever conteúdos, processos de aprender e de ensinar e a reflexão sobre a ação. In: ALMEIDA FILHO, J. C. P. Quatro Estações no Ensino de Línguas. Pontes. Campinas, 2012, p. 31-55.

AMORIM, G. B.; FINARDI, K.R. Internacionalização do ensino superior e línguas estrangeiras: evidências de um estudo de caso nos níveis micro, meso e macro. Avaliação, Campinas, SP, v. 22, n. 03, p. 614-632, 2017.

BYRAM, M. Teaching and assessing intercultural communicative competence. Bristol: Multilingual matters, 1997. 
BYRAM, M. Conceptualizing Intercultural (comunicative) competence and intercultural citzenship. In: JACKSON, J. (org) The Routledge Handbook of Language and Intercultural Communication. Abingdon: Routledge, 2011.

CROZET, C; LIDDICOAT, A. et al. The challenge of intercultural language teaching: Engaging with culture in the classroom. Striving for the third place: Intercultural competence through language education. Melbourne: Language Australia, 1999, p.113125.

DALFOLVO, M. S.; LANA, R. A.; SILVEIRA, A. Métodos quantitativos e qualitativos: um resgate teórico. Revista Interdisciplinar Científica Aplicada, Caxias do Sul, v.2, n.4, p. 01$13,2008$.

DUBIN, F. OLSHTAIN, E. How goals become realized through instructional plans. In: DUBIN, F. OLSHTAIN, E. Developing programs and materials for language learning. Cambridge: Cambridge University Press., 1986, p. 40-67.

DUBOC, A. P. FERRAZ, D. M. Letramento crítico e formação de professores de inglês: currículos e perspectivas em expansão. In: JORDÃO, C. M. (org) Dossiê especial. JORDÃO (org.) Letramentos e Multiletramentos no Ensino de Línguas e Literaturas. Revista X, 2011,1 .

FINARDI, K; SANTOS, J.; GUMARÃES, F. A relação entre línguas estrangeiras e o processo de internacionalização: evidências da Coordenação de Letramento Internacional de uma Universidade Federal. Interfaces Brasil/Canadá. Canoas, v. 16, n. 1, p. 233-255, 2016.

FRYE, D. Participatory Education as a Critical Framework for an Immigrant Women's ESL Class. Tesol Quartely, v. 33, n.3, p.501-512, 1999.

GALANTE, Angelica. Intercultural communicative competence in English language teaching: Towards validation of student identity. BELT-Brazilian English Language Teaching Journal, v. 6 n. 1, p. 29-39, 2015.

HAMMOND, J. MACKEN-HORARIK, M. Critical Literacy: Challenges and Questions for ESL Classrooms. Tesol Quartely, v. 33, n.3, p.501-512, 1999.

HOUSE, J. What is an 'Intercultural Speaker'. In: SOLER, E. A. JORDÀ, M. P. S. (org) Intercultural language use and language learning. Springer, Dordrecht, 2007, p.7-21.

JORDÃO, C. M. Abordagem comunicativa, pedagogia crítica e letramento crítico - farinhas do mesmo saco? In: ROCHA, C. H. MACIEL, R. F. (org) Lingua estrangeira e formação cidadã: por entre discursos e práticas. Coleção novas perspectivas em linguística aplicada, Campinas: Pontes, 2013, p. 69-90.

JORDÃO, C. M. FOGAÇA, F. C. Ensino de inglês, letramento crítico e cidadania: um triângulo amoroso bem sucedido. Linguas e Letras, v.8, n.14, p.79-105, 2007.

KRAMSCH, C. Third culture and language education. In: COOK, V. W., L. (orgs.) Contemporary applied linguistics, Londres: Continuum, 2009, p.233-254. 
KRAMSCH, C. The symbolic dimensions of the intercultural language teaching Language Teaching, v. 44, n.3, p. 354-367, 2011. Disponível em: $<$ http://journals. cambridge.org/action/displayAbstract?fromPage $=$ online $\&$ aid $=8271738>$. Acesso em: 20 de out. 2018.

KRAMSCH, C. Culture in foreign language teaching. Iranian Journal of Language Teaching Research, v.1, n.1,p. 57-78, 2013.

LEFFA, V. J.; IRALA, V. B. O ensino de outra(s) língua(s) na contemporaneidade: questões conceituais e metodológicas. In: LEFFA, V.J.; IRALA, V.B. (Orgs.). Uma espiadinha na sala de aula: ensinando línguas adicionais no Brasil. Educat: Pelotas, 2014, p. 21-48.

LIDDICOAT, A. J. Language Teaching and Learning from an Intercultural Perspective. In: HINKEL, E (org) Handbook of Research in Second Language Teaching and Learning. Abingdon: Routledge, 2011.

MARRARA, T. Internacionalização da Pós-Graduação: objetivos, formas e avaliação. Revista Brasileira de Pós-Graduação (RBPG), Brasília, v.4, n.8, p.245-262, 2007.

MARQUES, L. dos S.; ROZENFELD, C.C. de F. O uso de seriados televisivos no ensino de alemão: aspectos linguísticos, socioculturais, ideológicos e político-sociais em Deutschland 83. Pandaemonium Germanicum. [online], v.21, n.33, p.64-86, 2018. Disponível em: < http://www.scielo.br/pdf/pg/v21n33/1982-8837-pg-21-33-00064.pdf > Acesso em: 28 abr. 2019

MARQUES-SCHÄFER, G.; ROZENFELD, C.C.F. In: Marques-Schäfer, G.; e Rozenfeld, C. C. de F. (Orgs.). Ensino de línguas e tecnologias móveis: políticas públicas, conceitos, pesquisas e práticas em foco. São Paulo: Edições Hipótese, 2018. p. 52- 75

MYLES, J.; CHENG, L. The social and cultural life of non-native English speaking international graduate students at a Canadian university. In: Journal of English for Academic Purposes, v.2, n.3, p.247-263, 2003.

MONTE-MÓR, W. Reading Dogville in Brazil: Image, Language and Critical Literacy. Language and Intercultural Communication, v.6, n. 2, p.124-135, 2006.

MONTE-MÓR, W. Linguagem digital e interpretação: perspectivas epstemológicas. Trabalhos em Linguística Aplicada. v. 46, n.1, p. 31-44, 2007.

O'DOWD, R. Intercultural communicative competence through telecollaboration. The Routledge Handbook of Language and Intercultural Communication, Abingdon: Routledge, 2011, p.342-358.

OLIVEIRA, A. P. Tips for Teaching Culture in a Globalized World. In: LIMA, D. C. (Ed.). Language and its cultural substrate: perspectives for a globalized world. Campinas: Pontes, 2012, p. 83-107.

RICHARDS, J. C. Course planning and syllabus design. In: Curriculum development in language teaching. Cambridge: Cambridge University Press. 2011, 145-169. 
ROZENFELD, C. C. F. O ensino de alemão em escolas públicas pela perspectiva do letramento crítico: um subprojeto PIBID em foco. In: Pandaemonium Germanicum, v.19, n. 27, p.148-174, 2016.

SALOMÃO, A. C. B. O componente cultural no ensino e aprendizagem de línguas: desenvolvimento histórico e perspectivas na contemporaneidade. Trabalhos de Linguística Aplicada, Campinas, v.54, n.2, p.361-392, 2015.

SOARES, M. Letramento e alfabetização: as muitas facetas. Revista Brasileira de Educação, 2004, 25, 5-17. Disponível em: $<$ http://dx.doi.org/10.1590/S1413$24782004000100002>$ Acesso em: 13 jul. 2018.

SOUZA, L. M. T. M. O professor de inglês e os letramentos no século XXI: métodos ou ética. In: JORDÃO, C. M. MARTINEZ, J. Z. HALU, R. C. (org) Formação Desformatada Práticas com Professores de Língua Inglesa. Coleção novas perspectivas em linguística aplicada. Campinas: Pontes, 2011, p. 279-302

STEPHAN, C. W.; STEPHAN, W. G. Reducing intercultural anxiety through intercultural contact. International Journal of Intercultural Relations, 1992, v.16, n. 1, p.89-106.

STREET, B. Autonomous and ideological models of literacy: Approaches from New Literacy Studies. Media Anthropology Network, v.17, p.1-15, 2006.

TAGATA, W. M. Letramento crítico, ética e ensino de língua inglesa no século XXI: por um diálogo entre culturas. Revista Brasileira de Linguística Aplicada, v.17, n.3, p.379-403, 2017.

TAVARES, R. R. Conceitos de cultura no ensino/aprendizagem de línguas estrangeiras. Língua, cultura e ensino. Maceió: EDUFAL, 2006.

UNESCO. Diretrizes de políticas para a aprendizagem móvel. Organização das Nações Unidas para a Educação, a Ciência e a Cultura (UNESCO). Tradução para o Português. Unesco no $\quad 2014.2$ Disponível em: $<$ http://unesdoc.unesco.org/images/0022/002277/227770por.pdf $>$. Acesso em: 28 abr. 2019. 


\section{APÊNDICE A: Planejamento do minicurso}

\section{A minissérie Unsere Mütter Unsere Väter e o retrato da segunda guerra mundial}

Descrição geral: O minicurso preparado tem como foco o ensino e reflexão sobre as culturas alemãs e brasileiras para alunos inciantes de língua alemã. Nesse contexto, a cultura estrangeira é ensinada não apenas com o objetivo de evitar-se um mal-entendido na comunicação, mas também para levar o aluno a criação de uma nova perspectiva sobre si e o outro, desafiando conhecimentos e concepções prévias. Assim, a língua estrangeira adquire o caracter de instrumento para comunicação tanto quanto para interpretação e reflexão sobre práticas, produtos e perspectivas próprias e do outro. Para que isso seja possível, é necessário que o aluno participe ativamente das discussões propostas pelo professor ou mesmo proponha novos temas para diálogo em sala de aula. Essas discussões serão desenvolvidas a partir do visionamento do primeiro episódio da minissérie alemã Unsere Mütter Unsere Väter, a qual trata do tema da Segunda Guerra Mundial e seus impactos para o povo alemão. A partir de atividades como o visionamento da minissérie, interpretação de textos escritos e multimodais e discussões em grupos, pretende-se chegar aos objetivos gerais e especificos relatados a baixo. Embora um número grande de atividades anteriores e posteriores a exibição da minissérie esteja sugerida abaixo, pretende-se que o professor adapte tais atividades conforme o interesse, contexto e nível linguístico de seus alunos, além do tempo de aula.

Público: Alunos de alemão do curso de Letras da Unesp Araraquara do nível A1

Material: Minissérie Unsere Mütter Unsere Väter, projetor para exibição da minissérie, lousa, xerox, aparelhos celulares dos alunos.

Duração: 6 horas

Objetivo geral: desenvolvimento da reflexão crítica e competência intercultural no aluno de alemão a partir do visionamento e discussão da minissérie Unsere Mütter Unsere Väter.

Objetivos específicos: Possibilitar o desenvolvimento das seguintes atitudes, conhecimentos e habilidades dos alunos: 1. Abrir-se para novas perpectivas sobre a cultura e história alemã; 2. Adquirir conhecimentos sobre a memória nacional da Alemanha; 3. Expressar interpretações sobre o desenvolvimento da narrativa e dos personagens da minissérie; 4. Relacionar acontecimentos representados na minissérie com a realidade presente do aluno; 5 . Revisar preconceitos e estereótipos sobre a cultura-alvo.

\section{PRIMEIRA EXIBIÇÃO (0MIN-38MIN DO PRIMEIRO EPISÓDIO)}

\section{Atividades para preparação da primeira exibição:}

1.Colocar o título "Unsere Mütter Unsere Väter" na lousa e pedir que os alunos opinem sobre o que se trata a série.

Caso seja necessário, apresentar estruturas como: Es geht um... (Isso se trata... )/ Es ist über... (Isso é sobre...) / Es zeigt... (Isso mostra...)

2. Mediante o título "Unsere Mütter Unsere Väter", esclarecer que a minissérie trata da segunda guerra mundial e perguntar porque acham que esse nome foi escolhido.

Caso seja necessário, apresentar estruturas como: Ich denke, ... (Eu acho...)/Ich glaube, ... (Eu acredito...)/Vielleicht ist es... (Talvez seja...)

\section{Atividades durante a exibição}

1.Pedir que os alunos observem, logo no início da exibição, quem são os personagens, quais seus nomes e profissões, quais as primeiras impressões sobre eles, suas características, entre outros.

Caso seja necessário, relembrar vocabulário relativo a qualidades/adjetivos, como: Gut (bom), Böse (mal), Neugerig (curioso), Schön (bonito), Faul (folgado), etc.

2. Em um segundo momento, ao fim do episódio, retomar as características e perguntar quais das suas impressões sobre os personagens mudaram e quais se mantiveram.

Atividades após a primeira exibição: 
1.Perguntar aos alunos o que acharam do seriado, se tem dúvidas de vocabulário ou em relação a narrativa.

2.Dividir os alunos em 5 grupos para elaborar uma "Rad der Identität" (Roda da identidade) dos protagonistas da minissérie. A partir das rodas elaboradas na lousa, fazer perguntas que levem os alunos a discutir como se deu a perda ou não de determinados aspectos da identidade dos personagens durante os acontecimentos da minissérie, em especial após as repressões do regime nazista e os eventos nos frontes de guerra.

3.Discutir com os alunos sobre se ou como a sociedade brasileira hoje contribui para o mesmo processo de perda da identidade, a partir da violência ou preconceito. As discussões podem também partir do relato de experiências dos próprios alunos de características ou partes de sua identidade que precisaram abandonar ou esconder em determinados momentos de sua vida.

4.Discutir com os alunos o que acharam da aula, o que poderia ser mudado ou acrescentado.

Obs: as discussões finais, deviso a sua natureza mais complexa, poderão ser feitas em portugues ou alemão, dependendo do nível de conhecimento linguístico da sala

SEGUNDA EXIBIÇÃO (38MIN-60MIN DO PRIMEIRO EPISÓDIO)

Atividades para preparação da segunda exibição:

1.Escrever perguntas na lousa sobre os grupos Partisans, para as quais as respostas poderão ser constatadas ao longo da exibição, embora não sejam respondidas diretamente. As perguntas podem ser: „Wer sind die Partisans?" "Was machen sie?“ „Warum sind sie gefählich?“, „Warum haben die Soldaten Angst von Ihnen?“ entre outras.

Atividades após a segunda exibição:

1.Perguntar aos alunos se tem dúvidas de vocabulário ou em relação a narrativa.

2. Pedir que respondam em dupla por escrito as perguntas anteriores a exibição. Caso ainda tenham dúvidas sobre as respostas, podem pesquisar sobre o tema na internet com auxilio de celulares, tablets e outros aparelhos.

Caso seja necessário apresentar aos alunos estruturas causais com “weil”, “denn” ou "da" para responder as perguntas.

3.Perguntar e discutir com os alunos se, além dos Partisans, eles perceberam alguma outra forma de resistência dos personagens no seriado?

Caso seja necessário, apresentar estruturas como: Ich denke, ... (Eu acho...)/Ich glaube, ... (Eu acredito...)/Vielleicht ist es... (Talvez seja...)

4.Mostrar fotos de Sophie Scholl e outros integrantes do grupo de resistência "Weiße Rose". A partir das fotos, perguntar aos alunos quem eles imaginam que sejam essas pessoas e quais foram seus papeis na guerra. Pedir que os alunos pesquisem na internet sobre o grupo com auxílio de aparelhos celulares, tablets, entre outros. Discutir com os alunos se as figuras históricas corresponderam ou não as suas expectativas. É possível ainda exibir um trecho do filme "Sophie Scholl - Die letzten Tagen"9* conforme selecionado pelo professor.

5.Discutir com os alunos o que acharam da aula, o que poderia ser mudado ou acrescentado para aulas seguintes.

\section{TERCEIRA EXIBIÇÃO (60MIN-90MIN DO PRIMEIRO EPISÓDIO)}

Atividades para preparação da terceira exibição:

Colocar perguntas como as seguintes na lousa e discutir com os alunos:

„Was erwarten die Deutsche vom Krieg? Wurden deine Hoffnungen Realität? Was ist wirklich passiert? Warum erwarten sie das?“

Atividades após a terceira exibição:

1.Exercício "Erwartung X Realität":

Os alunos serão divididos em 2 grupos e serão dadas a eles imagens dos personagens no início e final do episódio. A partir dessas imagens, os alunos deverão organizá-las em duas colunas,

\footnotetext{
${ }^{9} \mathrm{O}$ filme encontra-se disponível no youtube no link: $<\mathrm{https}: / / \mathrm{www}$. youtube.com $/$ watch? $\mathrm{v}=\mathrm{CxERwWy} 1 \mathrm{zWI}>$
} 
correspondentes as expectativas dos personages e realidade que foi encontrada por eles na guerra. Não haverá necessáriamente opções corretas, mas pretende-se que os alunos compreendam as imagens e legendas presentes nelas, estabelecendo interpretações coerentes.

2.Discutir com os alunos: "Was erwartet Greta? Wurde es Realität?"

3.Dar aos alunos a letra da Musica "Mein Kleines Herz". Perguntar dúvidas de vocabulário e perguntar aos alunos "Worum geht es in dem Lied?"

Caso seja necessário, apresentar estruturas como: Es geht um... (Isso se trata... ) / Es ist über... (Isso é sobre...)

4.Perguntar aos alunos porque acham que o partido nazista está interessado em financiar Greta e se isso se relaciona a letra da música.

5.Retomar as perguntas do início da aula, principalmente: "Was erwarten die Deutsche vom Krieg? Warum erwarten sie das?". E observar se houve mudanças nas considerações e perspectivas dos alunos.

6.Discutir com os alunos: „Was erwarten die Brasiliener vom Leben, Politik, Bildung, u.s.w.? Wurden deine Hoffnungen Realität? Was ist wirklich passiert? Warum erwarten sie das?“‘.

Sobre a avaliação: A avaliação deste minicurso não tem carater reprovatório. Constitui-se por uma redação na língua materna sobre um dos temas discutidos em sala de aula e uma auto-avaliação na língua-alvo. 